\title{
Variations of Remodeling in Response to Left Main Atherosclerosis Assessed With Intravascular Ultrasound In Vivo
}

\author{
Clemens von Birgelen, MD, * Sergei G. Airiian, MD, Gary S. Mintz, MD, \\ Wim J. van der Giessen, MD, PhD, David P. Foley, MB, MRCPI, PhD, \\ Jos R.T.C. Roelandt, MD, PhD, Patrick W. Serruys, MD, PhD, and \\ Pim J. de Feyter, MD, PhD
}

Histopathologic studies have demonstrated that vessels enlarge to compensate for an increase in plaque burden; this has been confirmed in vivo using intravascular ultrasound (IVUS). The initial studies suggested a biphasic course of lesion formation with (1) preservation of lumen dimensions up to a plaque burden of approximately $40 \%$, and (2) luminal narrowing as plaque burden further increases. In this study, we used IVUS and angiography to assess the extent of left main (LM) atherosclerosis in 107 patients undergoing catheter-based procedures of the left anterior descending or left circumflex coronary arteries. Using IVUS, atherosclerotic plaques were found in all LM arteries, but only $26(24 \%)$ had varying degrees of luminal narrowing on the angiogram. Nevertheless, there was an inverse relation

c oronary angiography is used to assess lesion formation ${ }^{1}$; however, early atherosclerosis is angiographically silent. ${ }^{2-5}$ Histopathologic studies of diseased arterial segments have demonstrated that compensatory enlargement of the vascular wall occurs to compensate for the accumulation of atherosclerotic plaque.2,6 Intravascular ultrasound (IVUS) provides transmural images of coronary vessels in vivo including the coronary vascular wall, the area of atherosclerotic plaque, accurate lumen dimensions, and the serial changes that occur with the atherosclerotic disease process. ${ }^{7-10}$ Intravascular and epicardial ultrasound studies of atherosclerotic coronary ${ }^{3,5,11-13}$ and peripheral arteries ${ }^{14-17}$ have provided insights into the consequences of plaque accumulation and mechanisms of lesion formation. Earlier studies have confirmed the initial histopathologic findings of a biphasic course of lesion formation: (1) early preservation of lumen dimensions until a plaque burden of approximately $40 \%$ is reached, and (2) luminal narrowing as plaque burden further increases. ${ }^{3,4,6}$ More recent studies have shown evidence that inadequate or absent compensa-

\footnotetext{
From the Thoraxcenter, University Hospital Rotterdam-Dijkzigt, Erasmus University Rotterdam, Rotterdam, The Netherlands; and the Washington Hospital Center, Washington D.C. Manuscript received August 24, 1997, and accepted August 29, 1997

* Current address: Department of Cardiology, University Hospital Essen, Hufelandstrasse 55, D-45147 Essen, Germany. Dr. von Birgelen is the recipient of a fellowship of the German Research Society (DFG, Bonn, Germany).

Address for reprints: Pim J. de Feyter, MD, PhD, Thoraxcenter, Bd 381 , P.O. Box 1738, University Hospital Rotterdam-Dijkzigt, 3000 DR Rotterdam, The Netherlands.
}

( $r=-0.62, p<0.0001)$ between the minimal lumen area and the plaque burden (i.e., plaque + media divided by total vessel area) that was not restricted to plaque burden values $>40 \%$ (or $>30 \%$ ), but persisted at plaque burden values of $20 \%$ to $40 \%$. In addition, LM arteries with a plaque burden $<40 \%$ had a similar total vessel area as did $L M$ arteries with a plaque burden $\geq 40 \%\left(22.9 \pm 6.1\right.$ vs $\left.21.8 \pm 4.8 \mathrm{~mm}^{2}, \mathrm{p}=0.30\right)$. These data suggest that lumen dimensions may not be preserved even if plaque occupies no more than $20 \%$ to $40 \%$ of the total vessel area. Thus, there is more variation in remodeling response during earlier stages of plaque accumulation within the LM artery than is commonly suggested. (C) 1997 by Excerpta Medica, Inc.

(Am J Cardiol 1997;80:1408-1413)

tory vascular enlargement may also be important in the development of arterial stenoses. ${ }^{12,13,15-18}$ The left main (LM) coronary artery is one of the most important targets of atherosclerotic plaque accumulation. ${ }^{5,6,19-25}$ In this study we used IVUS and quantitative coronary angiography to systematically assess the extent and characteristics of LM atherosclerosis in 107 patients undergoing catheter-based interventions of significant lesions of the left anterior descending or left circumflex coronary arteries.

\section{METHODS}

Patient population: Between August 1, 1995, and July 31, 1996, a prospective IVUS examination of the LM artery was performed in 107 patients. There were 84 men $(78 \%)$ and 23 women $(22 \%)$ who ranged in age from 32 to 80 years (mean $58 \pm 11$ ); all of them were symptomatic ( 87 had chronic stable angina and 20 unstable angina). This patient population represented a consecutive series of patients with IVUSguided coronary interventions of significant narrowings in the left anterior descending or circumflex coronary arteries. None were considered to have significant disease of the LM artery. This study was approved by the local council on human research. All patients signed a written informed consent form approved by the medical ethical committee of the University Hospital Rotterdam-Dijkzigt.

Intervention procedures and coronary angiography: All patients received $250 \mathrm{mg}$ of aspirin and 10,000 U of heparin intravenously. If the duration of the entire catheterization procedure exceeded 1 hour, the acti- 


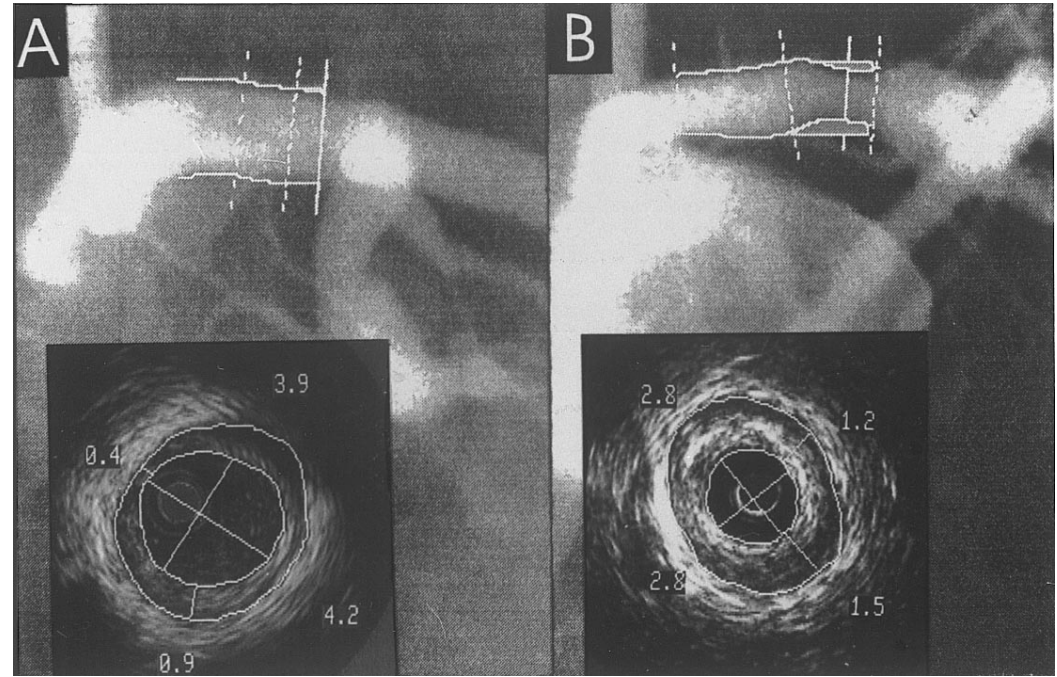

FIGURE 1. Examples of plaque formation in left main coronary arteries without $(A)$ and with (B) luminal narrowing on the angiogram. The angiograms display the plaque interpolation and minimal lumen detection, as obtained from quantitative coronary angiography. The intravascular ultrasound images (inserts) depict the site of minimum lumen cross-sectional area; on these images the contours of the lumen and total vessel boundaries as well as the minimum and maximum diameters of lumen and plaque + media were traced.

vated clotting time was measured; intravenous heparin was administered in order to maintain an activated clotting time of $>300$ seconds. In all patients, successful catheter-based interventions of lesions in the left anterior descending $(\mathrm{n}=91)$ or left circumflex coronary arteries $(n=16)$ were performed $(63$ with stent placement, 25 with directional atherectomy, and 19 with balloon angioplasty). At the end of the interventional procedure, intracoronary injection of $2 \mathrm{mg}$ of isosorbide dinitrate was administered, $\geq 2$ angiograms of the LM were recorded from opposite (ideally orthogonal) views without overlapping side branches or foreshortening, and the LM artery was interrogated using IVUS. There were no procedural or postprocedural in-hospital complications in these patients.

Angiographic analysis: The angiograms were first interpreted by 3 experienced coronary angiographers who were blinded to IVUS data. All angiographic projections were reviewed for the presence of atherosclerosis of the LM artery. If during the visual assessment of the LM artery, an indentation of the opacified luminal silhouette or a lumen narrowing of any degree was noticed, that LM artery was classified as "angiographically abnormal." Accordingly, only LM arteries without such findings were classified as "angiographically normal.' Decisions for classification required at least 2 votes.

Quantitative coronary angiography of 2 angiographic views (ideally orthogonal views without overlapping side branches or foreshortening) was then performed off-line. End-diastolic frames acquired after intracoronary application of nitrates and having homogeneous opacification of the coronary lumen were selected for analysis. The computer-based Coronary Angiography Analysis System (CAAS II, Pie Medical, Maastricht, The Netherlands) was used for the analysis. This has previously been described in detail. ${ }^{1}$

Intravascular ultrasound imaging: After intracoronary injection of $2 \mathrm{mg}$ of isosorbide dinitrate, the LM artery was examined using a mechanical IVUS system (CardioVascular Imaging Systems Inc, Sunnyvale, California) and a sheath-based IVUS catheter. The IVUS catheter incorporates a $30-\mathrm{MHz}$ beveled, single-element transducer rotating at $1,800 \mathrm{rpm}$ within a $2.9 \mathrm{Fr}$ long monorail imaging sheath. The distal 15$\mathrm{cm}$-long sonolucent segment of the imaging sheath has a common lumen that alternatively houses the guidewire (during catheter introduction) or the transducer (during imaging after the guidewire has been pulled back), but not both. This design avoids direct contact of the IVUS imaging core with the vessel wall. Before the IVUS imaging run, the guiding catheter was withdrawn from the ostium of the LM artery to assure complete scanning of the entire LM artery. All studies were performed using a motorized transducer pullback at $0.5 \mathrm{~mm} / \mathrm{s}$. All IVUS studies were recorded on 0.5 -inch high-resolution sVHS tape for off-line analysis.

Intravascular ultrasound analysis: Each videotape was analyzed off-line by an experienced IVUS analyst and overread by 2 independent cardiologists experienced in the use and analysis of IVUS images.

QUANTITATIVE ANALYSIS: Validation of manual measurements by IVUS has been reported previously. ${ }^{26}$ The site of the minimum lumen cross-sectional area was identified by carefully scrolling the tape back and forth; if there were multiple image slices with the same minimum lumen cross-sectional area, then the image slice with the largest plaque burden was selected. This was the image slice on which the IVUS measurements were performed (Figure 1). The crosssectional area measurements included the lumen and total vessel cross-sectional area (interobserver differences: $0.1 \pm 0.8 \mathrm{~mm}^{2}$ [lumen], $0.0 \pm 1.1 \mathrm{~mm}^{2}$ [total vessel]). Plaque + media cross-sectional area was calculated as total vessel minus lumen cross-sectional area, and the plaque burden was calculated as plaque + media divided by total vessel cross-sectional area. The total vessel diameter was calculated as: square root of [(4 $\cdot$ total vessel cross-sectional area)/ $\pi]$. The minimum and maximum lumen diameters (interobserver differences: $0.0 \pm 0.3 \mathrm{~mm}$ [minimum lumen], $0.0 \pm 0.3 \mathrm{~mm}$ [maximum lumen]), and the minimum and maximum plaque + media thickness (interobserver differences: $0.01 \pm 0.02 \mathrm{~mm}$ [minimum plaque + media], $0.01 \pm 0.09 \mathrm{~mm}$ [maximum plaque + media]) were measured. The total vessel cross-sectional area represents the area within the border between the hypoechoic media and the echoreflective adventitia. As in many previous studies using 


\begin{tabular}{|c|c|c|c|c|}
\hline & $\begin{array}{l}\text { All Patients } \\
(\mathrm{n}=107)\end{array}$ & $\begin{array}{l}\text { Plaque } \\
\text { Burden } \\
<40 \% \\
\text { (n }=71 \text { ) }\end{array}$ & $\begin{array}{l}\text { Plaque } \\
\text { Burden } \\
\geq 40 \% \\
(\mathrm{n}=36)\end{array}$ & p Value* \\
\hline \multicolumn{5}{|l|}{ IVUS } \\
\hline Lumen CSA $\left(\mathrm{mm}^{2}\right)$ & $15.1 \pm 4.8$ & $16.8 \pm 4.7$ & $11.6 \pm 2.8$ & $<0.0001$ \\
\hline$P+M C S A\left(\mathrm{~mm}^{2}\right)$ & $7.5 \pm 3.6$ & $6.1 \pm 2.9$ & $10.3 \pm 3.2$ & $<0.0001$ \\
\hline Total vessel CSA $\left(\mathrm{mm}^{2}\right)$ & $22.6 \pm 5.7$ & $22.9 \pm 6.1$ & $21.8 \pm 4.8$ & 0.30 \\
\hline Plaque burden (\%) & $33.3 \pm 12.9$ & $26.6 \pm 9.4$ & $46.6 \pm 7.3$ & $<0.0001$ \\
\hline $\begin{array}{l}\text { Minimum lumen diameter } \\
(\mathrm{mm})\end{array}$ & $3.91 \pm 0.75$ & $4.18 \pm 0.71$ & $3.38 \pm 0.54$ & $<0.0001$ \\
\hline $\begin{array}{l}\text { Maximum lumen diameter } \\
(\mathrm{mm})\end{array}$ & $4.65 \pm 0.75$ & $4.92 \pm 0.70$ & $4.12 \pm 0.54$ & $<0.0001$ \\
\hline$\underset{(\mathrm{mm})}{\text { Minimum } P}+\mathrm{M}$ diameter & $0.16 \pm 0.22$ & $0.08 \pm 0.15$ & $0.31 \pm 0.25$ & $<0.0001$ \\
\hline $\begin{array}{l}\text { Maximum } P+M \text { diameter } \\
(\mathrm{mm})\end{array}$ & $0.99 \pm 0.42$ & $0.85 \pm 0.37$ & $1.26 \pm 0.40$ & $<0.0001$ \\
\hline Total vessel diameter (mm) & $5.32 \pm 0.65$ & $5.36 \pm 0.68$ & $5.24 \pm 0.57$ & 0.34 \\
\hline Arc of plaque $\left({ }^{\circ}\right)$ & $296 \pm 83$ & $270 \pm 90$ & $348 \pm 22$ & $<0.0001$ \\
\hline \multicolumn{5}{|l|}{$\begin{array}{l}\text { Quantitative coronary } \\
\text { angiography }\end{array}$} \\
\hline $\begin{array}{l}\text { Minimum lumen diameter } \\
(\mathrm{mm})\end{array}$ & $3.84 \pm 0.78$ & $3.98 \pm 0.70$ & $3.59 \pm 0.86$ & $<0.05$ \\
\hline Reference diameter (mm) & $4.17 \pm 0.75$ & $4.30 \pm 0.68$ & $3.93 \pm 0.84$ & $<0.05$ \\
\hline Diameter stenosis (\%) & $8.0 \pm 7.0$ & $7.6 \pm 6.2$ & $8.8 \pm 8.3$ & 0.43 \\
\hline
\end{tabular}

and linear and nonlinear regression analyses. A p value $<0.05$ was considered statistically significant.

\section{RESULTS}

Overall angiographic and intravascular ultrasound data: With use of coronary angiography, only 26 LM arteries $(24 \%)$ were classified as abnormal; however, IVUS revealed atherosclerotic plaques in all $107 \mathrm{LM}$ arteries ( $p<0.0001$ vs angiography). Twenty-five plaques were classified as soft, 22 were fibrous, and 50 were mixed. Plaque calcification was found in $30 \mathrm{LM}$ lesions with an arc of calcium ranging from $20^{\circ}$ to $120^{\circ}$ in circumference. Data provided by both quantitative coronary angiography and IVUS are listed in Table I.

Data of angiographically normal versus abnormal main stems: The IVUS and quantitative coronary angiographic findings in patients with angiographically abnormal $(n=26)$ and normal LM arteries $(n=81)$ were then compared. The 2 groups were similar with regard to age $(59 \pm 10$ vs $57 \pm 11$ years $)$ and

IVUS, plaque + media cross-sectional area was used as a measure of atherosclerotic plaque, because ultrasound cannot measure media thickness accurately. ${ }^{27}$ The circumferential arc of the LM artery containing plaque was measured (in degrees) using a protractor centered on the lumen. The plaque burden has been termed cross-sectional area obstruction, cross-sectional narrowing, or percent plaque area by other investigators.

QUALITATIVE ANALYSIS: Plaque composition was assessed visually. The presence of significant amounts of calcium, dense fibrous tissue, or soft plaque was tabulated. Calcium produced bright echoes (brighter than the reference adventitia) with acoustic shadowing (attenuation) of deeper arterial structures ${ }^{8}$; the largest arc of calcium within the LM artery was identified and measured (in degrees) using a protractor centered on the lumen. Although initially an arc of calcium $>120^{\circ}$ was predetermined to be an exclusion criterion (to assure reliable measurement of the total vessel and plaque + media cross-sectional area), no patient had this degree of LM calcification. Plaque tissue producing echoes that were as bright as or brighter than the reference adventitia, but without acoustic shadowing was classified as "fibrous." Tissue being less dense than the reference adventitia was classified as "soft." Plaques containing more than 1 type of tissue were classified as "mixed."

Statistical analysis: Categorical variables were presented as frequencies. Continuous variables were presented as mean $\pm 1 \mathrm{SD}$. Categorical variables were compared using chi-square analysis. Continuous variables were compared using the 2-tailed Student's $t$ test gender (77\% vs $79 \%$ men). Patients with an angiographically abnormal LM artery had (1) a smaller quantitative angiographic minimal lumen diameter $(3.30 \pm 0.68$ vs $4.02 \pm 0.73 \mathrm{~mm}, \mathrm{p}<0.0001),(2) \mathrm{a}$ smaller quantitative angiographic reference diameter (4.01 \pm 0.74 vs $4.23 \pm 0.75 \mathrm{~mm}, \mathrm{p}<0.0001),(3) \mathrm{a}$ higher quantitative angiographic diameter stenosis $(17.60 \pm 6.85 \%$ vs $4.88 \pm 3.15 \%, p<0.0001)$, and (4) a smaller IVUS minimal lumen cross-sectional area $\left(13.0 \pm 4.9\right.$ vs $\left.15.7 \pm 4.7 \mathrm{~mm}^{2}, \mathrm{p}<0.05\right)$. In patients with an angiographically abnormal LM artery, the IVUS plaque burden tended to be higher $(37.2 \pm 14.2 \%$ vs $32.1 \pm 14.2 \%, p=0.10)$; however, the total vessel cross-sectional area tended to be even smaller $\left(20.9 \pm 6.4\right.$ vs $\left.23.1 \pm 5.4 \mathrm{~mm}^{2}, \mathrm{p}=0.10\right)$. There was no significant difference in plaque composition.

Assessment of vascular remodeling: The total vessel cross-sectional area by IVUS correlated directly with the plaque + media cross-sectional area $(r=0.54, p$ $<0.0001$, Figure 2).

In addition, the IVUS minimal lumen cross-sectional area correlated inversely with the plaque burden $(r=-0.62, p<0.0001$, Figure 3$)$; this relation was very similar for the LM artery with a plaque burden $\geq 40 \%(\mathrm{r}=-0.42, \mathrm{y}=-0.17 \mathrm{x}+19.0, \mathrm{p}<0.01)$ and for the LM artery with a plaque burden $<40 \%$ ( $\mathrm{r}=$ $-0.41, y=-0.21 x+22.3, p<0.001)$. Similar correlations were found for the LM artery with a plaque burden $\geq 30 \%$ and $<30 \%$ ( $\mathrm{r}=-0.48$ and -0.42 , respectively, both $\mathrm{p}<0.01$ ). Various nonlinear regression approaches were tested and did not reveal relations with higher or equal significance. 


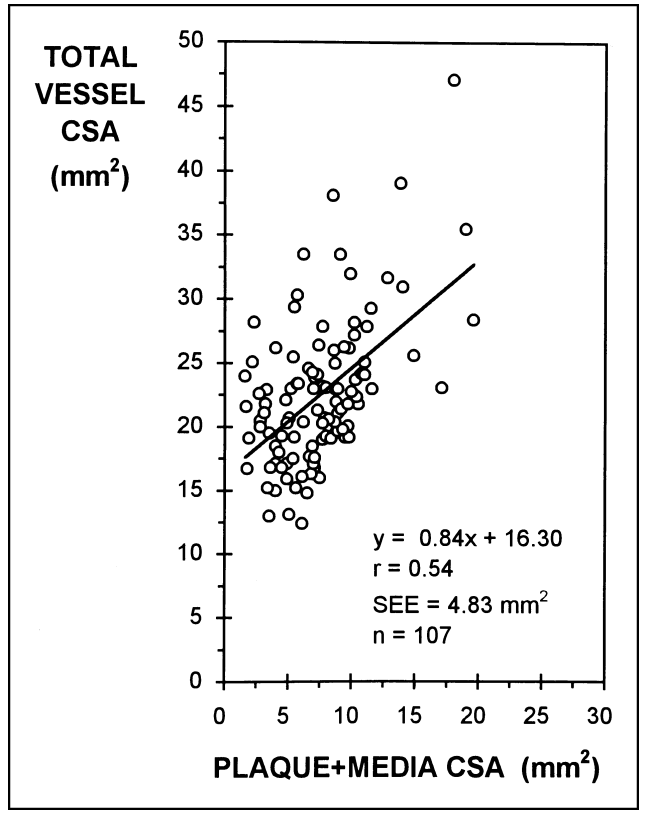

FIGURE 2. Correlation between total vessel cross-sectional area (CSA) and plaque + media cross-sectional area, measured with intravascular ultrasound in 107 left main coronary arteries.

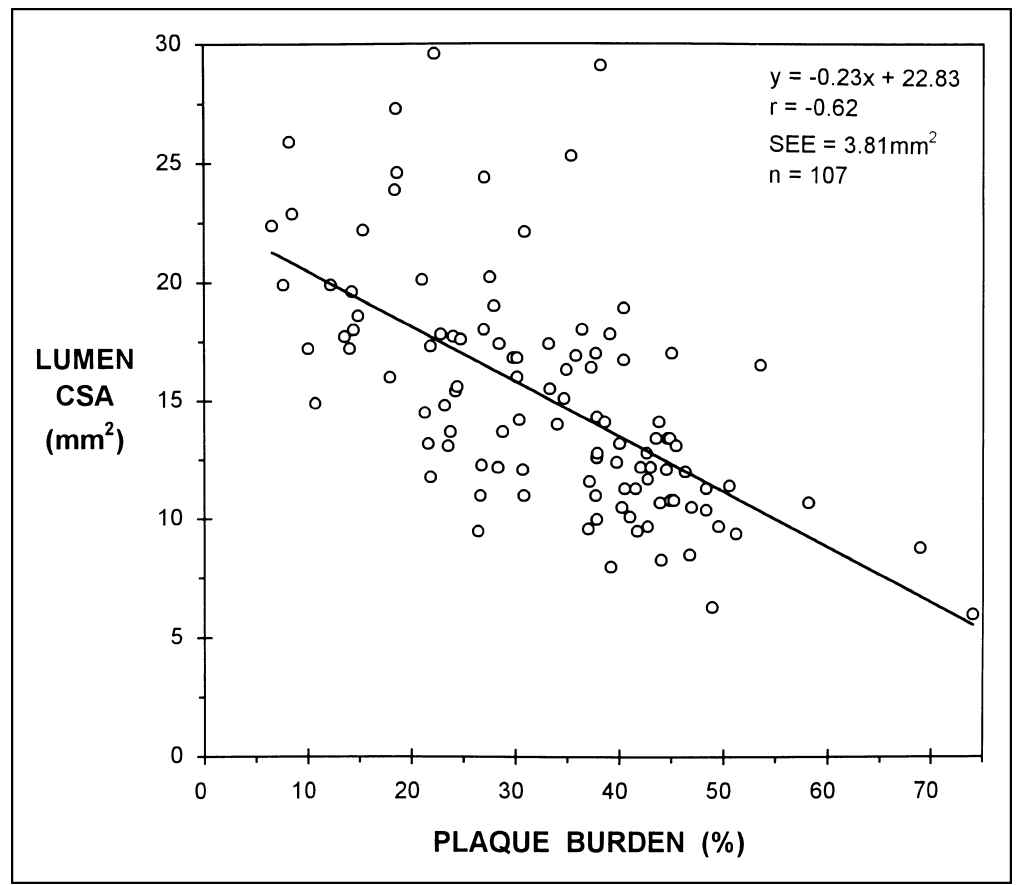

FIGURE 3. The minimal lumen cross-sectional area (CSA) by intravascular ultrasound correlated inversely with the plaque burden. This relation was observed not only in the 36 arteries with a plaque burden $\geq 40 \%(r=-0.42, p<0.01)$, but also in the 71 arteries with a plaque burden $<40 \%(r=-0.41, p<0.001)$. Similar correlations were also found for both, arteries with a plaque burden $\geq 30 \%$ and $<30 \%(r=-0.48$ and -0.42 , respectively, both $p<0.01)$.

Thirty-six of the $107 \mathrm{LM}$ arteries had an IVUS plaque burden $\geq 40 \%$; 71 had a plaque burden $<40 \%$. Both groups were similar with respect to age $(58 \pm 11$ vs $57 \pm 11$ years) and gender (79\% vs $78 \%$ men). Results of quantitative coronary angiography and IVUS analysis of these 2 subsets are listed in Table I. In the group with plaque burden $\geq 40 \%$, IVUS plaque composition was less frequently soft ( $8 \%$ vs $31 \%$, p $<0.01)$; the frequency of plaque calcification was higher $(47 \%$ vs $18 \%, \mathrm{p}<0.005)$, and the arc of diseased vessel wall was significantly larger $\left(348 \pm 22^{\circ}\right.$ vs $\left.270 \pm 90^{\circ}, \mathrm{p}<0.0001\right)$. In addition, in vessels with plaque burden $\geq 40 \%$, the lumen cross-sectional area and diameters were significantly smaller; the plaque + media cross-sectional area and diameters were larger, but the total vessel cross-sectional area was similar $\left(22.9 \pm 6.1\right.$ vs $\left.21.8 \pm 4.8 \mathrm{~mm}^{2}, \mathrm{p}=0.30\right)$.

\section{DISCUSSION}

In the present study, careful IVUS examination during catheter-based interventions of major epicardial left coronary arteries in a consecutive series of 107 patients revealed the presence of LM plaques in all and demonstrated the superiority of IVUS in detecting early atherosclerotic changes in vivo. ${ }^{1,2,8,19,20}$ These data are in agreement with previous IVUS findings in a smaller study group. ${ }^{19}$

Adaptive vascular remodeling: The absence of angiographic lumen narrowing despite the presence of ultrasound-confirmed plaque formation is generally thought to result from compensatory vascular enlargement. In addition, there were other signs of adaptive remodeling. First, the total vessel cross-sectional area measured $22.6 \mathrm{~mm}^{2}$; this is comparable to previous measurements in diseased LM arteries ( 22.0 to $23.3 \mathrm{~mm}^{2}$ ), ${ }^{3,20}$ but larger than measurements in nondiseased LM arteries $\left(19.0 \mathrm{~mm}^{2}\right) .{ }^{20}$ Second, despite an average plaque burden of $33 \%$, the average lumen cross-sectional area was reduced by $20 \%$ compared with that in nondiseased LM arteries. ${ }^{20}$

As in previous histopathologic and IVUS studies, ${ }^{2-6}$ we found a significant relation between plaque + media and total vessel cross-sectional area. This relation, which has previously been understood as an arithmetic expression of the adaptive remodeling process, appears to be less strong in the LM artery $(\mathrm{r}=0.46 \text { to } 0.56)^{3,5}$ than has been reported in other major epicardial coronary branches or in peripheral vessels $(\mathrm{r}=0.63$ to 0.85$) .^{2,3,14-16}$ In addition, the value of the relation between plaque + media and total vessel area appears to be limited because (1) correlating plaque + media with total vessel cross-sectional area should have a significant positive relation because this is a correlation between $\alpha$ and $\alpha+\beta$, and (2) the regression equation will always show steeper slopes for mildly diseased vascular segments, falsely suggesting overcompensation of total vessel area in relation to plaque accumulation. ${ }^{28}$

Variations of remodeling response: However, the results of the current study also suggest that even during earlier stages of atherosclerotic plaque accu- 


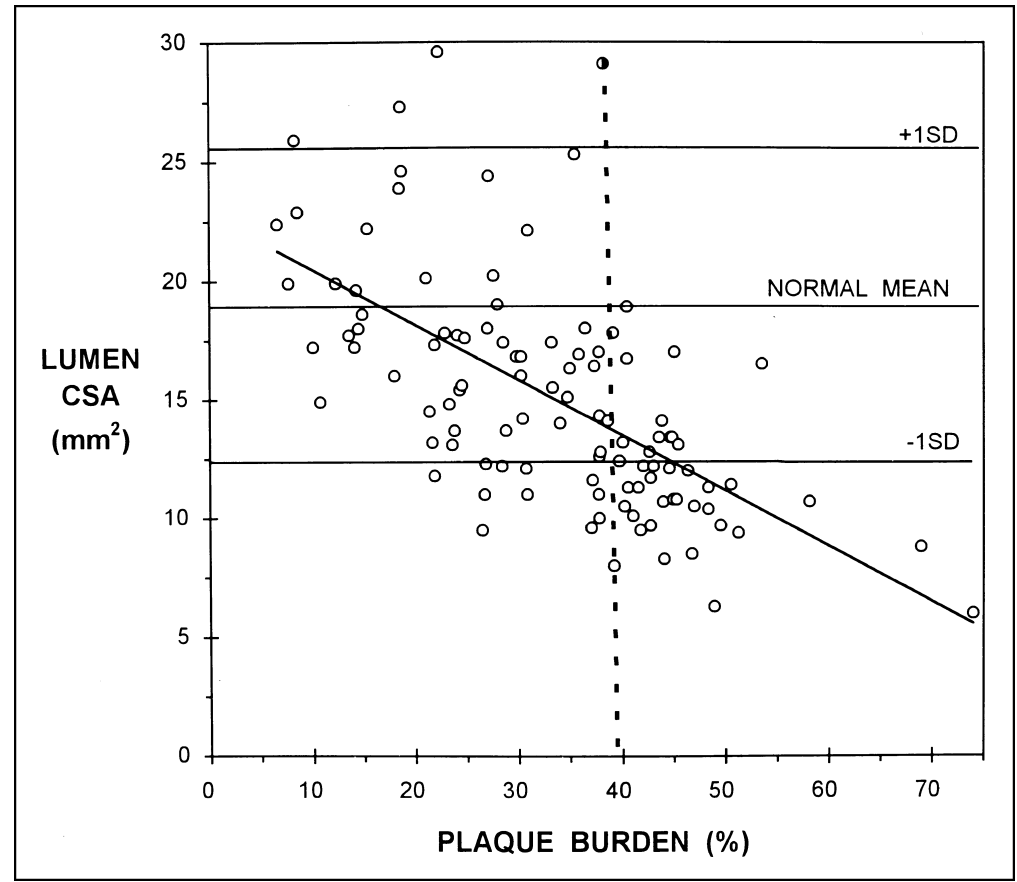

FIGURE 4. Intravascular ultrasound normal values from published reports, obtained in 61 main stems with ultrasound-documented absence of plaque formation $\left(19.0 \pm 6.5 \mathrm{~mm}^{2}\right), 20$ were used to evaluate the preservation of lumen crosssectional area (CSA). The illustration displays (1) data of the current study compared with (2) mean \pm 1 SD of the normal size (3 horizontal lines), (3) a linear regression line, and (4) a dotted line indicating a plaque burden of $40 \%$. In patients with a plaque burden $<20 \%$ the lumen size was evenly distributed on both sides of the mean normal value, and in all patients the lumen was larger than the - 1 SD margin. This may, to some extent, result from adaptive remodeling. Conversely, in several main stems with a plaque burden between $20 \%$ and $40 \%$, the lumen was smaller than the -1 SD margin, which may reflect inadequacy or early cessation of the adaptive remodeling process.

mulation (i.e., plaque burden of $20 \%$ to $40 \%$ ), compensatory vascular enlargement may be inadequate to preserve lumen dimensions in a considerable number of cases. For instance, there was a negative correlation between lumen cross-sectional area and plaque burden $(\mathrm{r}=0.62)$, a relation that was not restricted to patients with a plaque burden $>$ or $<30 \%$ or $40 \%$, as previously described. ${ }^{3,6}$ In the present study, there was also no significant difference in total vessel cross-sectional area between (1) LM artery with a plaque burden $<40 \%$ versus LM artery with a plaque burden $\geq 40 \%$, or (2) angiographically normal versus angiographically abnormal LM arteries. The total vessel crosssectional area was even slightly higher in the group with angiographically normal LM arteries. We used IVUS normal values from published data, obtained from $61 \mathrm{LM}$ arteries with IVUS-documented absence of plaque formation $\left(19.0 \pm 6.5 \mathrm{~mm}^{2}\right),{ }^{20}$ to evaluate the preservation of the lumen cross-sectional area. Figure 4 shows data of the current study compared with the mean $\pm 1 \mathrm{SD}$ of the normal LM size. In patients with a LM plaque burden $<20 \%$, the lumen size was evenly distributed on both sides of the mean normal value; in all patients the lumen was larger than the -1 SD margin. This may, to some extent, result from adaptive remodeling. Conversely, in several patients with a LM plaque burden between $20 \%$ and
$40 \%$, the LM was smaller than the -1 $\mathrm{SD}$ margin; this may reflect an inadequacy or an early cessation of the adaptive remodeling process.

Variability of the adaptive remodeling process has previously been suggested by others. ${ }^{6,12,15-17}$ Nevertheless, because these studies in humans were observations at one point in time, the time course and magnitude of vascular response to plaque growth remains unknown.

Limitations and potential sources of error: (1) All patients underwent catheterbased coronary interventions. Therefore, we were limited to assessment of LM arteries in patients without angiographically significant LM lesions, but with significant lesions of the left anterior descending or circumflex coronary arteries. (2) As in previous histopathologic or IVUS studies of vascular remodeling, ${ }^{1-18}$ this study was observational and provided only a "snapshot-like view" on coronary artery disease. (3) Measurement accuracy may be affected by an eccentric position or a noncoaxial orientation of the IVUS catheter. (4) The accuracy of visual assessment of plaque composition on conventional IVUS images is known to be limited, and IVUS tissue classification does not necessarily correspond to histologic classification. (5) Intracoronary injections of nitrates were used to prevent vasospasm, and no angiographic changes were observed before and after the IVUS imaging procedure; nevertheless, this does not completely exclude local vasospastic activity.

Clinical implications: Although IVUS inspection reveals the presence of plaque formation within the LM artery in patients undergoing procedures of major left coronary branches, the extent of plaque accumulation is variable and should not be equated with hemodynamically significant disease. Nevertheless, our findings underline the standard recommendation to perform any cannulation of the LM artery with care. The current study demonstrates that compensatory vascular enlargement is a variable phenomenon, explaining a smaller lumen cross-sectional area in some cases even before the plaque occupies $40 \%$ of the total vessel cross-sectional area. Serial IVUS studies will be necessary to gain insight into (1) the time course of vascular remodeling, and (2) whether plaques with different patterns of remodeling require specific or different therapy with respect to the acute procedural success and long-term outcome.

1. Escaned J, Baptista J, Di Mario C, Haase J, Ozaki Y, Linker DT, de Feyter PJ, Roelandt JRTC, Serruys PW. Significance of automated stenosis detection during quantitative angiography: insights gained from intracoronary ultrasound. Circulation 1996;94:966-972.

2. Stiel GM, Stiel LSG, Schofer J, Donath K, Mathey DG. Impact of compen- 
satory enlargement of atherosclerotic coronary arteries on angiographic assessment of coronary artery disease. Circulation 1989;80:1603-1609.

3. Hermiller JB, Tenaglia AN, Kisslo KB, Phillips HR, Bashore TM, Stack RS, Davidson CJ. In vivo validation of compensatory enlargement of atherosclerotic coronary arteries. Am J Cardiol 1993;71:665-668.

4. Ge J, Erbel R, Zamorano J, Koch L, Kearney P, Gorge G, Gerber T, Meyer J. Coronary artery remodeling in atherosclerotic disease: an intravascular ultrasonic study in vivo. Coron Artery Dis 1993;4:981-986.

5. Gerber TC, Erbel R, Gorge G, Ge J, Rupprecht HJ, Meyer J. Extent of atherosclerosis and remodeling of the left main coronary artery determined by intravascular ultrasound. Am J Cardiol 1994;73:666-671.

6. Glagov S, Weisenberg E, Zaris CK, Stankunavicius R, Kolettis GJ. Compensatory enlargement of human atherosclerotic coronary arteries. $N$ Engl $\mathrm{J} \mathrm{Med}$ 1987:316:1371-1375.

7. Fitzgerald PJ, St. Goar FG, Connolly AJ, Pinto FJ, Billingham ME, Popp RL, Yock PG. Intravascular ultrasound imaging of coronary arteries: is three layers the norm? Circulation 1992;86:154-158.

8. Mintz GS, Painter JA, Pichard AD, Kent KM, Satler LF, Popma JJ, Chuang YC, Bucher TA, Sokolowicz LE, Leon MB. Atherosclerosis in angiographically "normal" coronary artery reference segments: an intravascular ultrasound study with clinical correlations. J Am Coll Cardiol 1995;25:1479-1485.

9. de Feyter PJ, Ozaki Y, Baptista J, Escaned J, Di Mario C, de Jaegere PPT, Serruys PW, Roelandt JRTC. Ischemia-related lesion characteristics in patients with stable or unstable angina: a study with intracoronary angioscopy and ultrasound. Circulation 1995;92:1408-1413.

10. von Birgelén C, van der Lugt A, Nicosia A, Mintz GS, Gussenhoven EJ, de Vrey E, Mallus MT, Roelandt JRTC, Serruys PW, de Feyter PJ. Computerized assessment of coronary lumen and atherosclerotic plaque dimensions in threedimensional intravascular ultrasound correlated with histomorphometry. Am J Cardiol 1996;78:1202-1209.

11. McPherson DD, Sirna SJ, Hiratzka LF, Thorpe L, Armstrong ML, Marcus ML, Kerber RE. Coronary artery remodeling studied by high-frequency epicardial echocardiography: an early compensatory mechanism in patients with obstructive coronary atherosclerosis. J Am Coll Cardiol 1991;17:79-86.

12. Nishioka T, Luo H, Eigler NL, Berglund H, Kim CJ, Siegel RJ. Contribution of inadequate compensatory enlargement to development of human coronary artery stenosis: an in vivo intravascular ultrasound study. J Am Coll Cardiol 1996;27:1571-1576.

13. Wong CB, Porter TR, Xie F, Deligonul U. Segmental analysis of coronary arteries with equivalent plaque burden by intravascular ultrasound in patients with and without angiographically significant coronary artery disease. Am Cardiol 1995;76:598-601.

14. Losordo DW, Rosenfield K, Kaufman J, Pieczek A, Isner JM. Focal com pensatory enlargement of human arteries in response to progressive atherosclerosis: in vivo documentation using intravascular ultrasound. Circulation 1994 $89: 2570-2577$.
15. Pasterkamp G, Wensing PJW, Post MJ, Hillen B, Mali WPTM, Borst C. Paradoxical arterial wall shrinkage may contribute to luminal narrowing of human atherosclerotic femoral arteries. Circulation 1995;91:1444-1449.

16. Pasterkamp G, Borst C, Post MJ, Mali WPTM, Wensing PJW, Gussenhoven EJ, Hillen B. Atherosclerotic arterial remodeling in the superficial femoral artery: individual variation in local compensatory enlargement response. Circulation 1996;93:1818-1825.

17. Mintz GS, Kent KM, Pichard AD, Satler LF, Popma JJ, Leon MB. Contribution of inadequate arterial remodeling to the development of focal coronary artery stenoses: an intravascular ultrasound study. Circulation 1997;95:17911798 .

18. von Birgelen C, Di Mario C, Serruys PW. Structural and functional characterization of an intermediate stenosis with intracoronary ultrasound: a case of "reverse Glagovian modeling'". Am Heart J 1996;132:694-696.

19. Hermiller JB, Buller CE, Tenaglia AN, Kisslo KB, Phillips HR, Bashore TM, Stack RS, Davidson CJ. Unrecognized left main coronary artery disease in patients undergoing interventional procedures. Am J Cardiol 1993;71:173-176. 20. Ge J, Liu F, Gorge G, Haude M, Baumgart D, Erbel R. Angiographically "silent" plaque in the left main coronary artery detected by intravascular ultrasound. Coron Artery Dis 1995;6:805-810.

21. Lim JS, Proudfit WL, Sones FM Jr. Left main coronary arterial obstruction: long-term follow-up of 141 non-surgical cases. Am J Cardiol 1975;36:131-135. 22. Bulkley BH, Roberts WC. Atherosclerotic narrowing of the left main coronary artery. Necropsy analysis of 152 patients with fatal coronary heart disease and varying degrees of left main narrowing. Circulation 1976;55:823-828.

23. Conti CR, Selby JH, Christie LG, Pepine CJ, Curry RC Jr, Nichols WW, Conetta DG, Feldman RL, Mehta J, Alexander JA. Left main coronary artery stenosis: clinical spectrum, pathophysiology, and management. Prog Cardiovasc Dis 1979;22:73-106.

24. Isner JM, Kishel J, Kent KM, Ronan JA, Ross AM, Roberts WC. Accuracy of angiographic determination of left main coronary arterial narrowing: angiographic-histologic correlative analysis in 28 patients. Circulation 1981;63:10561064 .

25. Bergelson BA, Tommaso CL. Left main coronary artery disease: assessment, diagnosis, and therapy. Am Heart J 1995;129:350-359.

26. Hodgson J McB, Graham SP, Savakus AD, Dame SG, Stephens DN, Dhillon PS, Brands D, Sheehan H, Eberle MJ. Clinical percutaneous imaging of coronary anatomy using an over-the-wire ultrasound catheter system. Int J Cardiac Imaging 1989;4:186-193.

27. Mallery JA, Tobis JM, Griffith J, Gessert J, McRae M, Moussabeck O, Bessen M, Moriuchi M, Henry WL. Assessment of normal and atherosclerotic arterial wall thickness with an intravascular ultrasound imaging catheter. Am Heart J 1990;119:1392-1400.

28. Gussenhoven EJ, Geselschap JH, van Lankeren W, Posthuma DJ, Aad van der Lugt. Remodeling of atherosclerotic coronary arteries assessed with intravascular ultrasound in vitro. Am J Cardiol 1997;79:699-702. 